International Journal of English Literature and Social Sciences
Vol-7, Issue-1; Jan-Feb, 2022
Journal Home Page Available: https://ijels.com/
Journal DOI: $10.22161 / \mathrm{ijels}$

Peer-Reviewed Journal

\title{
Influence of Social Media on Adolescent Mental Health
}

\author{
Jasseer Jabbar', Shibu Dharmarajan², Ritu Priya Raveendranathan ${ }^{3}$, Devanand \\ Syamkumar ${ }^{4}$, Alisha Jasseer ${ }^{5}$
}

\author{
${ }^{1,3,4}$ University of Kerala. India. \\ ${ }^{2}$ Assumption University of Thailand \\ ${ }^{5}$ Calicut University, India \\ Corresponding author: sdharamarajan@au.edu
}

Received: 09 Dec 2021; Received in revised form: 12 Jan 2022; Accepted: 19 Jan 2022; Available online: 31 Jan 2022

C 2022 The Author(s). Published by Infogain Publication. This is an open access article under the CC BY license

(https://creativecommons.org/licenses/by/4.0/).

\begin{abstract}
Social media use during adolescence can adversely affect health and development. It could be safely assumed that social media is the most famous and preferred leisure activity among adolescents. Most teens report that social media gives positive contributions to their lives, but the modern research literature documented that social media use and adolescents' mental health are adversely connected. Social media is a double-edged sword, so it can affect their mental health in a constructive or destructive way. Hence the excess use of social media comes with some risks for adolescents. The present study found the impact of social media on adolescent mental health. Depression, anxiety, stress, and aggression have been found as mental health issues of adolescents. The participants for the present study were randomly chosen, consisting of $312(N=312)$ adolescents aged between 14 and 19 years randomly selected from Kerala, India. The variables like viz., social media use, Depression, Anxiety, Stress, and Aggression were selected for the study. The outcome of the study reveals that there is a positive correlation between social media use and depression ( $r=0.62)$, anxiety $(r=0.59)$, stress $(r=0.57)$, and aggression $(r=0.51)$. All the correlations were found to be statistically significant. The findings of the present research can be explained how mental health could be affected if the time spent on social media is considerably higher than usual.
\end{abstract}

Keywords-Adolescents, depression, mental health; social media, stress.

\section{INTRODUCTION}

People have an innate need to be recognized and embraced. People use social media to satisfy their socioemotional needs of acceptance and inclusion. Therefore, social media has taken a poignant position in everyone's lives. Social media's effect is such that it could effortlessly alter one's perspective regarding anything under the sky. As per Pew Research Centre (2015), 92 percent of teenagers are vigorous social media users. Lenhart et al. (2015) found that children between the age of 15-17 are predominantly heavy social media users. In another study, Lenhart (2015) has said that social media plays a substantial part in youngsters' daily lives. Surprisingly enough, such platforms have transformed into an essential space for development among adolescents and young adults.

It could be safely assumed that social media is the most famous and preferred leisure activity among adolescents. They are not just influenced by cyberspace and several media associated with it, but they turn into content makers or content creators. The engagement in the creation is a vigorous process inclusive of the constant involvement in constructing and reconstructing their identities. The heavy users, adolescents, are constantly involved in 'connecting', 'reconnecting' or 'unfriending' relationships. As a result of their choices and their decisions, they seem to be challenging, influencing, and thus transforming the 
cultural norms applied both offline and online (Galarneau, 2011, 2012; Rutledge, 2013).

\section{LITERATURE REVIEW}

The abundance of research shows that the younger generation of society uses social media platforms for selfpresentation and self-disclosure. Such behavior is interconnected to their personality, intimacy development, and well-being (Subrahmanyam \&Smahel, 2011; Michikyan\& Subrahmanyam, 2012; Bartsch \& Subrahmanyam, 2015). Social media use could facilitate the most significant developmental task of adolescence, i.e., identity formation. Cyberspace provides adolescents with an expansive opportunity to freely express different shades of their personality. The shades of their personalities disclose their real, ideal, and false selves (Michikyan, Dennis, \&Subrahmanyam, 2014). With the comfort inherently provided by an enclosed space (of their rooms) and their computer or mobile phone, adolescents consider it easy to find new and nuanced meaning thus continuously adding to their personality characteristics. For an adolescent who is constantly engaged in selfquestioning and self-doubting, a platform that gives the privilege to be anonymous is mostly seen as a savior of the difficult times. Additionally, it enables them to create a narrative of the constantly dwindling sense of self. Overall, such an engagement is seen as bringing some order and meaning to their complex life.

Being a double-edged sword, social media entails both positive and negative impacts. Social media use comes with some risks for adolescents. Moreno et al., 2011, observed that social media is related to depressive symptoms, stress (Egan \& Moreno, 2011), and social anxiety (Shaw, Timpano, Iran, \&Joormann, 2015). According to Schneider, Gruman, \&Coutts (2012), violent media can lead to a temporary escalation of aggressive thoughts or long-term emulation of aggressive behaviors. The time invested in social media is directly linked to poor sleep, low self-esteem, and an increase in depression, anxiety, and aggression. If not monitored or restricted, social media usage by adolescents can severely affect their overall wellness. Uncontrolled usage of social media among teens can lead to internet addiction.

Adolescents place great importance on peer relationships while mobile phones enable them to connect with their peers; they also feel intense pressure to respond to messages, posts, and other paraphernalia associated with social media. They fear losing social relationships since their sense of social belongingness will be in danger. The intensity of the pressure to remain in the virtual group is such a swift change of priorities among adolescents. The attention to health, safety, family, and academics takes a back seat. Huang $\mathrm{H}(2013)$ noted that out of $75 \%$ of teenage mobile phone users, $25 \%$ use it for social media, $54 \%$ for messaging, and another $24 \%$ uses for instant messaging. It is significant to note that many adolescents' socio-emotional development occurs whilst engaged on their mobile phones and the internet. The compulsivity to maintain and remain in a virtual group leads them to addiction. Problematic conduct associated with internet use is deemed in psychiatric terminology as 'dependence'. Social media addiction is considered a habitual disorder.

Adolescents' morning starts with scrolling through the social media pages (Osatuyi, \&Turel, 2018). One could sit for hours doing nothing but scrolling through the posts and pages on social media. The intensity of the addiction could react to a level where one could imagine having notifications in their head and pushing them to check their phone. Looking at the adolescents' perspective, a focus group study among 11-18 years by Michelle O'Reilly et al. (2018) reported that social media was seen as a threat to their mental wellness. Furthermore, three significant themes were recognized, i.e., a) they believed that it could cause mood and anxiety disorder, b) it was seen as a platform for cyberbullying, c) it was often framed as a sort of 'addiction'.

Kim (2017) noted that understanding social media effects on adolescents' wellness is of supreme importance because of the alarming mental health problem. Assessing the relationship between the use of social media and depressive symptoms among children and adolescents, a systematic review of 11 studies showed a significant relationship (McCrae, Gettings, \&Purssell, 2017). A Metaanalysis of 23 studies revealed an association between problematic Facebook use and psychological distress among adolescents (Marino et.al. 2018). Numerous studies have found a significant association between excess social media use and depression (Best et.al. 2014 \& Hoare et.al. 2016). Persons with mental health issues are prone to be physically inactive. Inactivity caused due to the use of the internet could increase the risk of mental health problems if overused. This finding was supported by Asare (2015). Social media users have multiple accounts leading them to do multitask. Rosen et.al. (2013) indicated that multitasking activities in online anticipate signs of mental disorders. Primack and EscobarViera (2017) revealed that the number of social media accounts and anxiety levels is correlated.

Hanprathet et al. (2015) observed a substantial nexus between depression and Facebook addiction among adolescents. Li et al. (2017) observed that insomnia has a mediating influence on social media addiction and 
depression. In a study, Wang et al. (2018) opined that social media addiction and depression are positively associated. It was found that poor self-esteem constituted the influence of dependence on depression through rumination. Lisa Barman, DiptaKanti Mukhopadhyay et al. (2018) observed that intense use of social networking sites, especially odd hours, was significantly linked to depression and anxiety. Pantic et al. (2012) observed among high school students that the time spent on Facebook and depression are correlated positively. Lou et al. (2012) showed that the intense use of Facebook predicted an increase in loneliness.

Certain inquiries noted that the use of social media predicts exaggerated mental health in the future (Vannucci, Flannery, \&Ohannessian, 2017; Coyne, Padilla, Holmgren, \& Stockdale, 2019), while in some other studies, mental health anticipated future use of social networking sites (Scherr, Toma, \& Schuster, 2018). Moreover, few other studies have obtained a bi-directional and longitudinal relationship between mental health and social media use (Frison, \&Eggermont, 2017; Nesi, Miller, \&Prinstein, 2017; Houghton et al., 2018). A significant investigation regarding the topic was conducted by Twenge, Joiner, Rogers, and Martin (2018), who investigated differences among generations in the use of social media and several outcomes in adolescents. The study revealed that the present generation (termed as 'Igen' for those who are 1995 born or later) shows a greater propensity to face depression, loneliness, sleep deprivation, and avoidance of adult roles than the previous generation. They also stated that the duration spent on social media could lead to a steep increase in problems of mental health in adolescents. In such a scenario, an inquiry to understand the impact of social media and adolescent mental health is vital.

\section{METHOD}

\section{Participants}

The participants for the investigation were randomly chosen, consisting of 312 adolescents belonging to the age group of 14-19 years. They were selected from schools and colleges in Kerala.

\section{Variables}

The variables like viz., social media use, depression, anxiety, stress, and aggression were selected for the study.

\section{Measures}

Three instruments were used for collecting the data. The details of the tools used are enumerated below:

a) Social Media Disorder Scale (Eijenden et al., 2016)

As a screening tool, the scale measures Social Media Disorder using 9 items based on the nine criteria for internet gaming disorder (DSM V,2013), viz., Preoccupation, Tolerance, Withdrawal, Persistence, Displacement, Problem, Deception, Escape, and Conflict, The scale claimed to have internal consistency, convergent and criterion validity, strong structural validity, and appropriate test-retest reliability.

\section{b) DAS Scale (Lovibond and Lovibond, 1995)}

It is a 21 item, four-point Likert scale which measures the intensity of depression, anxiety, and stress. The Internal consistency reliability of subscales of DAS was found to be $0.94,0.88$, and 0.93 for depression, anxiety, and stress, respectively. The Construct validity of DAS was found to be correlated with the indices of convergent validity $(0.65$ and 0.75).

\section{c) Aggression Scale (Roma Pal and Tasneem Naqvi, 1986)}

It is a 30 -item scale that identifies and evaluates different aspects of aggression among adolescents. Each item has five alternate answers, and it is graded on a five-point scale on the positive dimension and a zero point on the negative dimension. The reliability of the test was found to be 0.82 . The content validity of the items has been collected through expert opinion.

\section{Statistical techniques}

To determine the correlation between social media use and adolescent mental health problems, Pearson Product Moment Correlation was computed.

\section{RESULTS AND DISCUSSION}

The current study investigated the correlation between social media use and mental health among adolescents. Mental health concerns such as depression, anxiety, stress, and aggression have been assessed in the study. To assess the relationship between these variables a Pearson Product Moment Correlation (r) was employed. The results of the same are illustrated in the table given below. 
Table 1: Correlation among the study variables

\begin{tabular}{|l|l|l|l|l|l|l|l|l|}
\hline Variables & $\begin{array}{l}\text { Social media } \\
\text { Disorder }\end{array}$ & Depression & Anxiety & & & Stress & Aggression \\
\hline $\begin{array}{l}\text { Social media } \\
\text { Disorder }\end{array}$ & 0 & & & & & & \\
\hline Depression & $0.62^{* *}$ & 0 & & & & & \\
\hline Anxiety & $0.59^{* *}$ & $0.75^{* *}$ & 0 & & & & \\
\hline Stress & $0.57^{* *}$ & $0.61^{* *}$ & $0.69^{* *}$ & & & 0 & \\
\hline Aggression & $0.51^{* *}$ & $0.49^{* *}$ & 0.14 & & & 0.06 & 0 \\
\hline
\end{tabular}

The results show that the social media use is positively correlated with depression $(\mathrm{r}=0.62)$, anxiety $(\mathrm{r}=0.59)$, stress $(r=0.57)$, and aggression $(r=0.51)$. All the correlations were found to be statistically significant. The results indicated that the adolescents who engage in problematic use of social media experience symptoms of depression, anxiety, stress, and aggression. The results were substantiated by many research findings (Kim, 2017; McCrae, Gettings, Purssell, 2017; Marino, Gini, Vieno, \&Spada, 2018). This may be since the current generation is dependent on social media. Because of their restricted selfregulation capacity and their susceptibility to peer pressure, teenagers are at a higher risk of facing backlash in overusing social media, and therefore, they are at a higherof developing a mental disorder.

Kraut et.al. (1998), Nie and associates (2002), Robinson et.al. (2002), and Baym (2010) proved that social media has an impact on adolescents' mental health. But Anderson and his colleagues (2017) mentioned that the impact reduces inter-personal interaction, promotes addiction-related behaviors. cyberbullying, and social comparison led to social pressure. Furthermore, due to the elevated exposure to suicide stories on social media, it poses a threat of contagion effect (Bell, 2014).

Vidal et.al. (2020) summarized the findings of many studies which revealed that the time spent on social media and depression are positively correlated. SampasaKanyinga\& Lewis (2015), Sampasa-Kanyinga\&Hamilton (2015), noted that frequent use of social media, i.e., greater than or equal to 2 hours a day, was positively linked to suicidal ideation and para-suicide. Lee et.al. (2017) additionally found links to self-regulation arrears in adolescents due to excess usage of social media. Factors such as the number of social media accounts and the frequency of visits to sites are associated with depression. (Barry, Sidoti Briggs, Reitor, \&Lindsey, 2017).

Wang et al. (2018) concluded that social media use and depression are mediated by rumination in adolescents with low self-esteem. Scott (2016) found that nighttime engagement in social media was related to poor quality of sleep, anxiety, and symptoms of depression. Wood and Scott (2016) noted that excessive social media users experience poor quality of sleep, weak self-esteem, and greater levels of anxiety and depression.

Aggressive behavior is a general problem among young internet users ( $\mathrm{Ku}$ et al., 2012; Hindiya\&Patchin, 2013). Cyberbullying is an antisocial behavior intended to inflict pain, boredom, and behavioral imbalance. Cyberbullying is general and has a significant impact on adolescents' wellness (Cappadocia et.al 2013; Kowalskiet. al. 2014; Tsitsika et al., 2015; Hanm et al., 2015). The problemgenerating use of social media leads adolescents to get involved in overt-reactive and instrumental aggression and reported escalatedlevels of different kinds of victimization (Martinez-Ferrer, Moreno, \&Musitu, 2018).

The findings of the present research can be explained based on Lins'sdisplacement hypothesis and use and gratification theory. Lins's (1993) displacement hypothesis suggests that the hours spent on social media have the potential to displace other essential activities such as sleep (Scott, \&Woods, 2018) or face-to-face interaction with friends (Twenge, 2017). This concept explains how mental health could be affected if the hours invested on social media is considerably higher than usual. In contrast to the displacement hypothesis, the uses and gratification theory (Katz et.al. 1974) posits that poor mental health is linked with the future use of social media (Quan-Hasse\&Young 2010; Bulut\&Dogan, 2017). The same perspective considers individuals as active choosers of social media, with everyone actively choosing to be a part of which particular social media so that their needs are fulfilled. According to the displacement hypothesis, social media usage is nothing but a means of escapism and digression from ordinary life (Coyne et.al. 2013). In such a situation, to avoid pain and stress, a teenager may decide to connect with others online through social media. They turn to social media to alleviate the pain. 


\section{CONCLUSION}

Adolescence is one of the most stressful and strain instances of a person's life. Adolescents engage in a variety of recreational activities to reduce or avoid that stress. In today's world, social media is the main entertainment zone of these people. This study reveals the consequences of excess usage of social media. In the wake of such alarming research, the current research implies that excess use of social media may adversely affect adolescents' mental health.

\section{REFERENCES}

[1] Aalbers, G., McNally, R. J., HeerenA., de Wit, S.,\&Fried,E.I.(2019). Social media and depression symptoms: A network perspective. Journal of Experimental Psychology: General. 148: 1454-1462. DOI: https ://doi.org/10.1037/xge0000528

[2] American Psychiatric Association, DSM5 Task Force.(2013). Diagnostic and statistical manual of mental disorders: DSM-5 ${ }^{\mathrm{TM}}(5$ th $\quad$ ed.). American Psychiatric Publishing, Inc.DOI: https://doi.org/10.1176/appi.books.9780890425596

[3] Anderson, C. A., \&Bushman, B. J. (2018).Media Violence and the General Aggression Model, Journal of Social Issues. 74: 386-413. DOI: hops://doi.org/10.1111/josi.12275

[4] Asur, S., \&Huberman, B. A. 2010. Predicting the Future with social media. (2010). IEEE/WIC/ACM International Conference on Web Intelligence and Intelligent Agent Technology. 492-499. DOI: https://doi.org/10.1109/WHAT.2010.63

[5] Banyai, F., Zsila, A., Kiraly, 0., Maraz, A., Elekes, Z., Griffiths, M. D., Andreassen, C. S., \&Demetrovics, Z. (2017). Problematic social media use: Results from a large-scale nationally representative adolescent sample. PLOS ONE. DOI: https://doi.org/10.1371/journal.pone.0169839

[6] Barman, L., Mukhopadhyay, D., \& Bandyopadhyay, G. (2018). Use of social networkingsite and mental disorders among medical students in Kolkata, West Bengal. Indian Journal of Psychiatry. 60: 340.DOI: https://doi.org/10.4103/psychiatry.IndianJPsychiatry_210 $-18$

[7] Carr,C.T.,\&Hayes,R.A.(2015).Social Media: Defining, Developing, and Divining. Atlantic Journal of Communication. DOI: https://doi.org/10.1080/15456870.2015.972282

[8] Coyne, S. M., Rogers, A A, Zurcher, ). D., Stockdale, L., \& Booth, M. 2020. Does time spent using social media impact mental health? Aneight -year longitudinal study. Computers in Human Behavior.104:106160.DOI:https://doi.org/https://doi.org/ 10.1016/j.chb.2019.106160

[9] Erreygers,S.,Vandebosch,H.,Vranjes, I.,Baillien, E., \& De Witte,H.(2017).Nice orNaughty? The Role of Emotions andDigital $\mathrm{Me}$ dia Use in Explaining Adolescents' Online Prosocial and Antisocial Behavior. Media Psychology.20: 374- 400. DOI: https://doi.org/10.1080/15213269.2016.1200990

[10] Gruman, J.A.,Schneide r,F.W.,\& Coutts,L.M.(2017).AppliedSocialPsychology:Understanding and Addressing Social and Practical Problems. In Applied Social Psychology: Understanding and Addressing Socialand Practical Problems. SAGE Publications, Inc. DOI: https:// doi.org/10.4135/9781071800591

[11] H uang, H. (2013). Social media addiction and socio psychologicaltraits. Social Media Generationin Urban China. 77-102.DOI: https://doi.org/10.1007/978-3-64245441-7_5

[12] Keles, B., McCrae, N., \&Grealish, A. (2020). A systematic review: the influence of socialmedia on depression, anxiety, and psycho logical distress in adolescents. International Journal of Adolescence and Youth.25:7993.DOI: https://doi.org/10.1080/02673843.2019.1590851

[13] Lovibond, S.H. and Lovibond, P.F. (1996). Manual for the Depression Anxiety Stress Scales.

[14] Martinez -Ferrer,B., Moreno,D.,\&Musitu, G.(2018). Are Adolescents Engagedin the Problematic Use of Social Networking Sites More Involved in Peer Aggression and Victimization? Frontiersin Psychology. 9: 801. DOI: https://doi.org/10.3389/fpsyg.2018.00801

[15] McCrae,N.,Gettings,S.,\& Purssell,E.(2017).Social Mediaand Depressive Symptomsin Childhood and Adolescence: A Systematic Review.In Adolescent Research Review. DOI: https://doi.org/10.1007/s40894-017-0053-4

[16] Michikyan, M.,\&Suarez -Oro zco,C.(2016). Adolescent Mediaand Social Media Use. Journal of Adolescent Research.31:411 $-414$. https://doi.org/10.1177/0743558416643801

[17] O'Reilly, M., Dogra, N., Whiteman, N., Hughes, J.,Eruyar,S.,\&Reilly,P.(2018). Is social media bad for mental health and well being? Exploring the perspectives of adolescents. Clinical Child Psychology and Psychiatry.23:601613.DOI: https://doi.org/10.1177/1359104518775154

[18] Pantie,I.,Damjanovic,A.,Todorovic,J.,Topalovic,D.,Bojovico vic, D., Ristic, S.,\& Pantie, S.(2012).Association between online social networking and depression in high school students: behavioral physiology viewpoint. Psychiatria Danubina.24:90-93. DOI: http://www.ncbi.nlm.nih.gov/pubmed/22447092

[19] Vidal, C., Lhaksampa, T., Miller, L., \& Platt, R. (2020). Social media use and depression inado les cents: a scoping review. In International Review of Psychiatry. DOI: https://doi.org/10.1080/09540261.2020.1720623

[20] Woods,H.C.,\&Scott,H.20 1 6.\#S Leyte ns: Social media use in adolescence is associated with poor sleep quality, anxiety, depression, and low self-esteem. journal of Adolescence. 51: 41-49. DOI: https://doi.org/10.1016/j.adolescence.2016.05.008 